\title{
Subjective well-being of Indonesian and Swedish college students: A cross-cultural study on happiness
}

A’yuninnisa, Rizqi Nur'aini $\bowtie$

Gadjah Mada University, Indonesia (rizqi.ayuninnisa@gmail.com)

Adrianson, Lillemor

University of Borås, Sweden (Lillemor.Adrianson@hb.se)

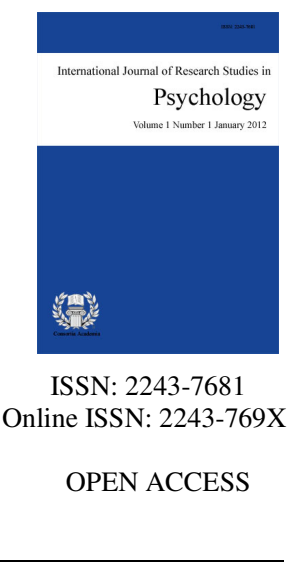

Received: 9 April 2019

\section{Abstract}

This study aimed to explore and compare levels of subjective well-being and contributing factors that promote happiness in two countries, Indonesia and Sweden. A total of 104 Swedish and 112 Indonesian college students participated in this study. The instruments used were Positive and Negative Affect Schedule (PANAS; Watson, Clark, \& Tellegen, 1988), Satisfaction with Life Scale (Diener, Emmons, Larsen, \& Griffin, 1985), and an open-ended question, "What are the three most important things in your life that make you happy?" Data analyses were conducted in two phases for qualitative and quantitative data. Two major themes, interdependent and dependent factors of happiness, emerged from the qualitative data. Results showed that respondents from both countries reported interdependent factors as their main happiness contributor. The quantitative result demonstrated no significant effects on subjective well-being for culture and its interaction with the happiness factor. Instead, only the happiness factor had a significant effect on subjective well-being. People with interdependent happiness were happier than those who pursue independent happiness factors. This study observed no difference in the level of subjective well-being and happiness factors across the cultures.

Keywords: happiness; subjective well-being; interdependent happiness; Indonesia; Sweden 


\section{Subjective well-being of Indonesian and Swedish college students: A cross-cultural study on happiness}

\section{Introduction}

Studies have found a variation in the level of subjective well-being in some countries (Diener, Diener, \& Diener, 1995; Diener, Napa-Scollon, Oishi, Dzokoto, \& Suh, 2000), which was affected by the income levels of the countries (Diener, Diener, \& Diener, 1995). However, instead of actual income, subsequent studies found culture as the main factor that affects the level of subjective well-being (Diener \& Oishi, 2000; Ye, $\mathrm{Ng}, \& \mathrm{Liana}$, 2015). As proposed by Diener, Oishi, Richard, and Lucas (2003), cognitions and emotions are always situated in a specific cultural context.

Culture is commonly classified into two main groups, namely, individualistic and collectivistic, based on the values possessed by society (Triandis, 1995). Certain dimensions can also characterize the culture of nations (Hofstede \& Hofstede, 2005). A growing number of studies found that people in individualistic countries tend to have a higher level of subjective well-being compared with people in collectivistic countries (Diener, Diener, \& Diener, 1995; Uchida, Norasakkunkit, \& Kitayama, 2004; Sheldon et al., 2004). Besides, the variation of happiness across nations was also due to some cultural dimensions such as femininity (Arrindell, 1998), power distance, uncertainty avoidance, and future orientation (Ye et al., 2015).

Notwithstanding the numerous findings on happiness across cultures, exploring the way happiness differs between one culture and another is necessary. The variation level of happiness may be due to differences in conceptualization (Oishi, Graham, Kesebir, \& Galinha, 2013) and ways to strive toward happiness (Uchida et al., 2004). Thus, portraying the causes or factors that contribute to happiness across cultures is important. A qualitative study could be implemented as an alternative to explore and elaborate on this type of data. In addition, most cross-cultural studies were conducted in Western Europe, North America, and East Asian countries. Other regions of the world such as Africa, Arabia, or Southeast Asia remain underexplored (Suh \& Oishi, 2004).

Regarding the needs for more cross-cultural studies on happiness, this study aimed to explore the subjective well-being in Indonesia and Sweden by comparing the level of subjective well-being and exploring factors that may contribute to the happiness of people in each culture.

\subsection{Subjective well-being and its components}

Subjective well-being, which is popularly known as happiness, can be generally defined as an individual's evaluation of his/her life (Lucas \& Diener, 2008), which comprises a process of reflection about the ideal and actual conditions involving retrospective memory (Kahneman, Diener, \& Schwarz, 1999). According to Diener, Suh, Lucas, and Smith (1999), subjective well-being consists of two dimensions: cognition and affect. The cognitive dimension involves the individual's evaluation made by an individual about one's life satisfaction, while the affective dimension refers to moods and emotions reflected on the events in one's life, which comprises two components called positive affect and negative affect. Those components of subjective well-being are related but separable (Diener, 1984).

Diener (1984) proposed that positive and negative affects are not the same elements nor do they lie on the same continuum, particularly when the time-frame increases (Diener \& Emmons, 1984). Some studies applying factor analyses found that although these two poles of affect are moderately inversely correlated, they are clearly separable (Diner, Smith, \& Fujita, 1995; Gallagher, Lopez, \& Preacher, 2009; Kokko, Korkalainen, Lyyra, \& Feldt, 2013).

Numerous studies also investigated the correlation of dimensions of subjective well-being and psychological 
states. Diener, Sandvik, and Pavot (2009) suggested that people with a high degree of happiness would have a high frequency of positive affect and infrequency of negative affect. Several studies also found a positive relationship between positive affect and life satisfaction and a negative relationship between these two dimensions of subjective well-being with negative affect, stress, and depression (Chapin \& Hulbert, 2009; Hamama, Ronen, Shachar, \& Rosenbaum, 2013). Proctor, Linley, and Maltby (2010) found that people with a higher score on happiness tend to have a lower score on depression, negative affect, and social stress. Considering these studies, we may conclude that components of subjective well-being are correlated to each other and related to people's mental state. Happy people tend to feel infrequent negative affect, highly frequent positive affect, and are satisfied with their lives, while less happy people tend to experience mental health problems.

\subsection{Happiness and culture}

Triandis (1995) proposed two types of culture, individualistic and collectivistic, based on how individuals perceive themselves in a social relationship. Focusing on almost the same concept, Markus and Kitayama (1991) use the terms "independent" and "interdependent self-construal". People in an individualistic culture usually have independent self-construal and view themselves as relatively independent of other people and express themselves as unique. This characteristic is usually found in Western cultures such as in North America and Western Europe. By contrast, people in a collectivistic culture have interdependent self-construal and view themselves as related to other people in society. This type of culture governs the behavior of people in regions such as Asia, Africa, Latin America, and Southern Europe.

According to Hofstede and Hofstede (2005), culture has six dimensions. Two of these are power distance and masculinity versus femininity. Every nation has a different score in every dimension. Power distance means that every member of society has power in accordance with social expectation. High power distance means that inequality and hierarchy among people are expected and desired. Masculinity versus femininity entails social preference for achievement, assertiveness, and material reward in achieving success. Having a high score on masculinity indicates high assertiveness and achievement oriented.

Regarding the characteristics of cultures and values held by individuals, researchers have elaborated the concept of happiness in a given society. In the collectivistic cultures, people tend to have social harmony and relationship as factors contributing to promote their happiness. Although they are less motivated to look for personal happiness, they are more motivated to pursue communal and intersubjective forms of happiness (Lu \& Gilmour, 2004; Uchida et al., 2004), which are described as interdependent happiness. These values are mostly found in Asian collectivistic cultures. In these cultures, people usually pursue the fulfillment of role obligations in interdependent social relationships (Kitayama, Park, Sevincer, Karasawa, \& Uskul, 2009), creation and maintenance of interpersonal harmony, and striving to promote the welfare and prosperity of the collective (Lu \& Gilmour, 2004). In other words, people in collectivistic cultures are likely to be happy by receiving care and support from others.

On the other hand, in the Western cultures of North America and Europe, people tend to pursue happiness and have the freedom to do so. They are supposed to be independent persons who master and control their external environment, realize their potentials, and create and achieve goals. People consider achievement and positivity of personal self-development as factors that make them happy (Lu \& Gilmour, 2004). They also are more motivated to achieve personal happiness and experience more positive emotions than people in collectivistic cultures. Thus, the average levels of subjective well-being are higher in individualistic than in collectivistic cultures (Diener, Diener, \& Diener, 1995; Uchida et al., 2004).

Some empirical studies have validated these notions and found explanations for the cultural differences in the level of subjective well-being. Sheldon et al. (2004) showed that in a collectivistic culture (such as Korea, China, and Taiwan), people had a lower level of subjective well-being than those who live in an individualistic 
culture (United States). Supporting this finding, the study by Wirtz, Chiu, Diener, and Oishi (2009) found that European-Americans had a tendency to recall positive affect more often than Asian-Americans who also recalled negative affect. Americans also tended to take responsibility for positive events more than Japanese people who were more likely to attribute negative events to the self. In addition, regarding the cognitive component of subjective well-being, people from individualistic cultures tend to overestimate their judgment of life satisfaction, while people from collectivist cultures underestimated their life satisfaction (Diener et al., 2003).

Alternative explanations of the way subjective well-being vary across cultures may be due to different ways of conceptualizing happiness as well as the factors promoting happiness. Regarding happiness, Lu and Gilmour (2004) found that people in an individualistic (America) and a collectivistic (China) culture basically defined happiness in the same way as a positive emotion experienced in a certain moment of time. However, some differences were observed in the expression of happiness. For example, Chinese people tended to express happiness during a longer period of time than Americans did. Chinese were more likely to control self-excitement and maintain group harmony. Furthermore, the Chinese and Americans had distinct ways of conceptualizing and valuing happiness.

Oishi and Diener (2001) found several factors that promote subjective well-being in different cultures. The individualistic people were more likely to pursue independent activities for their own enjoyment, while the collectivistic people were more likely to engage in interdependent activities with their family or friends. Furthermore, Oishi and Diener (2003) observed that the individualistic people had higher frequency of feeling positive emotions compared with the collectivistic people. The reason is that the individualistic people were more likely to select situations and tasks that were enjoyable and brought happiness.

A more recent study conducted by Ye et al. (2015) tried to explore the happiness of people living in different countries by considering several dimensions of culture as defined by Hofstede and GLOBE. They used subjective well-being data generated by the World Values Survey on some countries and found that culture is an important explanatory variable for subjective well-being. Based on their findings, power distance correlated significantly negatively with subjective well-being. Countries with higher power distance tend to be less happy than those that have lower power distance. Gender equality is also a cultural issue because it is positively related to subjective well-being.

\subsection{Indonesian and Swedish cultures}

Indonesia is considered as a collectivistic country with interdependent self-construal, while Sweden is considered as an individualistic country with dependent self-construal (Markus \& Kitayama, 1991; Triandis, 1995). These characteristics can be demonstrated by the fact that Swedes have the autonomy to decide without any intervention from others, while in the same situations, Indonesians mostly ask for considerations from people when making decisions. Based on Hofstede's cultural dimensions, Indonesia has high scores on collectivism and power distance, as well as a higher score on masculinity compared to Sweden, which has a high score on individualism, a low score on power distance, and a lower score on masculinity (Hofstede \& Hofstede, 2005).

\subsection{Current study}

The goal of this study was to understand the happiness of people in Indonesia and Sweden by exploring the contributing factors that promote happiness. This study also aimed to investigate whether a difference existed between the two cultures in terms of happiness factors and level of happiness. Thus, this study proposes the following hypotheses:

H1: The life satisfaction of the Swedish respondents is higher than that of the Indonesian respondents.

H2: The frequency of positive affect of the Swedish respondents is higher than that of their Indonesian 
Subjective well-being of Indonesian and Swedish college students: A cross-cultural study on happiness

counterparts.

H3: The frequency of negative affect of the Swedish respondents is lower than that of their Indonesian counterparts.

H4: The Swedish respondents have a higher level of subjective well-being than the Indonesian respondents.

H5: A difference exists between the cultures with regard to factors that contribute toward promoting people's happiness in relation to their happiness.

To test the hypotheses, this study was divided into two phases of data analysis. The first phase used a qualitative question to explore possible explanations for life matters that made the people in each culture happy. In the second phase, all of the hypotheses were tested to understand in what way happiness differed between the cultures. The data collection was conducted once for both studies.

\section{Phase 1: Qualitative study}

\subsection{Participants}

This study aimed to explore the factors that make people in each culture happy. By applying a convenience sampling towards college students in the two countries, a total of 112 Indonesian students (44 male and 68 female participants, mean age 21 years) and 104 Swedish students (26 male and 78 female participants, mean age 26 years) were involved. Among the Swedish participants, 15 were excluded from the study due to incomplete filling of the questionnaire.

\subsection{Instruments}

An open-ended question, "What are the three most important things in your life that make you happy?" was asked to gather the data.

\subsection{Analysis}

The qualitative answers from the respondents were categorized by three coders using thematic analysis based on the themes gathered from the responses. From three responses given by each participant, the first answer was the only one analyzed as it is believed to represent overall answers in qualitative data (Krippendorff, 2004).

\subsection{Results}

Data of the qualitative answers generated several themes, which were then categorized into two main themes, namely, independent and interdependent factors (see Table 1). Interdependent factor was a label given to a group of categories including life matters that made the respondents happy and which seemed to involve interaction between respondents and their social world. The categories under this theme were people, pets, and social life. The dependent factor was a label given to a group of categories including matters that made the respondents happy and which seemed to be experienced by the respondents themselves. The categories under this theme were self-improvement, activities, religion and principle, physical matters, materials, life condition, and self-autonomy.

The data suggest that a higher number of the Swedish respondents mentioned interdependent instead of independent as the factor that made them happy. A consistent result was also observed in the responses of the Indonesian subjects. This finding showed that both the Swedish and Indonesian respondents considered the interpersonal aspects as the main elements that contribute toward promoting their happiness. 
A’yuninnisa, R. N., \& Adrianson, L.

\section{Table 1}

Themes that emerged from qualitative answers as life aspects that make people happy

\begin{tabular}{llcccc}
\hline \multirow{2}{*}{ No. Category } & \multicolumn{3}{c}{ Culture } \\
\cline { 3 - 6 } & & 85 & 85.9 & \multicolumn{2}{c}{ Indonesia (\%) } \\
\hline \multirow{2}{*}{2} & Interdependent factor & 71 & 68.3 & 60 & 69.6 \\
& People and pets & 14 & 13.5 & 18 & 16.1 \\
\multirow{2}{*}{2} & Social interaction and love & 14 & 14.1 & 34 & 30.4 \\
& Dependent factor & 2 & 1.9 & 11 & 9.8 \\
& Self-improvement & 3 & 2.9 & 6 & 5.4 \\
& Activities & 0 & 0.0 & 9 & 8.0 \\
& Religion and principle & 5 & 4.8 & 3 & 2.7 \\
& Physical matters & 3 & 2.9 & 1 & 0.9 \\
& Materials & 0 & 0.0 & 3 & 2.7 \\
& Life condition & 1 & 1.0 & 1 & 0.9 \\
& Self-autonomy & 5 & 4.8 & 0 & 0.0 \\
\hline Total & Blank & 104 & 100.0 & 112 & 100.0 \\
\hline
\end{tabular}

\subsection{Discussion}

Phase 1 of the study aimed to explore the aspects that promote happiness among Indonesians and Swedes. Results of qualitative answers generated two main themes: dependent and interdependent factor. A surprising finding emerged from the data. Both groups of respondents reported interdependent factor rather than dependent factor as the primary matter in life that made them happy. Hitoko and Uchida (2015) call this condition interdependent happiness, which is experienced when people are happy through the achievement of interdependent goals. This type of happiness is usually felt by collectivistic people with relational orientation (Kitayama et al., 2009; Markus \& Kitayama, 2001).

Interestingly, our finding suggested that interdependent happiness can also be experienced by people with independent self-construal. The finding provides a different point of view compared to the previous studies, which mostly suggested that people in individualistic cultures tend to pursue personal happiness while collectivistic people tend to pursue communal happiness (Diener, Smith, \& Fujita, 1995; Lu \& Gilmour, 2004; Uchida et al., 2004). According to our findings, both cultures tend to reflect upon their communal happiness. Although people in Sweden are more likely to value independence, they might be happier if they could achieve their interdependent goal as the expectation of the society. The possible explanation for this result is that Sweden is a country with a high score in femininity, as Hofstede and Hofstede (2005) claimed. People achieve their personal goals and achievements in a manner that is not solely for themselves. Swedes appreciate equality, which prompts them to think about people around them. Caring for others is a dominant value emphasized in society. Thus, warm interpersonal relationships are important in people's lives.

\section{Phase 2: Quantitative study}

\subsection{Instruments}

Satisfaction with Life scale (Diener, Emmons, Larsen, \& Griffin, 1985) is a 7-point Likert scale measuring global life satisfaction. The scale consists of five questions on overall judgment of life. A high score indicates that the respondents have a high degree of life satisfaction. In our study, the Cronbach's alpha coefficient for the scale was .80. The internal consistency for Indonesian and Swedish respondents were .78 and .82, respectively.

The Positive and Negative Affect Schedule (PANAS) was constructed based on the work of Watson, Clark, and Tellegen (1988) about affect and consisted of 10 statements containing positive affects and 10 statements comprising negative affects on a 7-point Likert scale with the endpoints "infrequent" to "frequent". The scores of 
negative and positive affects were summarized for each respondent. A high score on positive affect indicated that the respondents had high frequency of positive affect in their lives, while a high score on the negative affect indicated that the respondents had low frequency of positive affect in their lives. The Cronbach's alpha coefficient was .78 for the positive affect and .83 for the negative affect. However, internal consistency scores were diverse between the Indonesian and Swedish respondents. The reliabilities of positive affect were .80 for the Indonesian respondents and .77 for the Swedish respondents, while the reliabilities of negative affect were .83 for the Indonesian respondents and .82 for the Swedish respondents.

\subsection{Analysis}

First of all, themes that emerged from the qualitative data in Phase 1 were transformed into a categorical variable called "happiness factor" as this variable would be included in the data analysis in Phase 2. In addition, a new variable called "subjective well-being" was considered as a composite score derived from three variables: life satisfaction, positive affect, and negative affect. Each score of the variable was transformed into $z$-score. The subjective well-being score was formulated by adding the $z$-score of life satisfaction and positive affect, and then subtracting them with the negative affect score. The hypotheses for Phase 2 were then analyzed using $t$-test to observe the way in which the scores of the dependent variables differed across the group of respondents. Two-way ANOVA was also used to examine whether or not an interaction occurs between category variables on the happiness and affect scores.

\subsection{Results}

Data of the qualitative answers generated several themes, which were then categorized into two main themes, namely, independent and interdependent factors (see Table 1). Interdependent factor was a label given to a group of categories including life matters that made the respondents happy and which seemed to involve interaction between respondents and their social world. The categories under this theme were people, pets, and social life. The dependent factor was a label given to a group of categories including matters that made the respondents happy and which seemed to be experienced by the respondents themselves. The categories under this theme were self-improvement, activities, religion and principle, physical matters, materials, life condition, and self-autonomy.

The data suggest that a higher number of the Swedish respondents mentioned interdependent instead of independent as the factor that made them happy. A consistent result was also observed in the responses of the Indonesian subjects. This finding showed that both the Swedish and Indonesian respondents considered the interpersonal aspects as the main elements that contribute toward promoting their happiness. Table 2 shows the means, standard deviations, and correlation matrix. At a glimpse, all the variables are correlated with one another. Life satisfaction has a moderate positive relationship with positive affect. The negative affect is correlated negatively with other variables.

\section{Table 2}

Descriptive Statistics and Correlations of Variables

\begin{tabular}{|c|c|c|c|c|c|}
\hline Variables & $M$ & $\mathrm{SD}$ & 1 & 2 & 3 \\
\hline Age & 23.54 & 6.21 & & & \\
\hline Life Satisfaction & 23.63 & 5.36 & -- & & \\
\hline Positive Affect & 52.93 & 6.87 & $.47 * *$ & -- & \\
\hline Negative Affect & 34.00 & 9.37 & $-.28 * *$ & $-.19 * *$ & -- \\
\hline
\end{tabular}

Note. $N=216 .{ }^{* *} p<.01$

The first assumption, that the Swedish respondents have a higher degree of life satisfaction than the Indonesian respondents, was not confirmed in an independent $t$-test. The mean score of the Indonesian 
respondents $(M=23.46, \mathrm{SD}=5.35)$ was not significantly different at $t(214)=.48$ from that of the Swedish respondents $(M=23.82, \mathrm{SD}=5.39)$. The results showed that the Swedish respondents were not more satisfied with their life than the Indonesian respondents.

The following hypotheses were proposed to further investigate happiness among the respondents in terms of their affects. The second hypothesis was not confirmed in a $t$-test $t(214)=-.322$. The mean score of the Indonesians' positive affect $(M=53.07, \mathrm{SD}=6.80)$ was not different from the mean score of the Swedes' $(M=$ $52.77, \mathrm{SD}=6.98)$. The results showed that the Swedish respondents experienced relatively the same frequency of positive emotion as the Indonesian respondents. However, the third hypothesis, that the Swedish respondents have less frequency of negative affect than the Indonesian respondents, was confirmed in a $t$-test with negative affect as the dependent variable. The mean score of the Indonesian respondents $(M=35.84, \mathrm{SD}=8.88)$ was significantly higher at $t(214)=-3.06$, two-tailed $p=.003$ than that of the Swedish respondents $(M=32.01, \mathrm{SD}=$ 9.52). The results showed that the Indonesian respondents experienced more negative affect than the Swedish respondents did.

In addition, the fourth hypothesis, that the Swedish respondents have a higher degree of subjective well-being than the Indonesian respondents, was also not confirmed in an independent $t$-test with culture as the independent variable and composite score of subjective well-being as the dependent variable. The Indonesian respondents had relatively the same degree of subjective well-being at $(t(214)=1.43, M=-.21, \mathrm{SD}=2.22)$ with the Swedish respondents $(M=.22, \mathrm{SD}=2.18)$. The results showed that the Swedish respondents were not happier than the Indonesian respondents.

The fifth hypothesis, that there is a difference between the cultures with regard to happiness factors in relation to happiness, was confirmed in a two-way ANOVA, with culture and happiness factors as independent variables and the composite score of subjective well-being as the dependent. The result showed that a main significant effect was obtained only for happiness factors $(\mathrm{F}(1,211)=10.108, p<.01)$ but not for culture $(\mathrm{F}(1,211)=.118)$ and their interaction $(\mathrm{F}(1,211)=1.47)$. Respondents who reported interdependent factor as life matters that made them happy were more likely to show higher subjective well-being than those who reported dependent factor as matters that contributed to their happiness.

\subsection{Discussion}

Phase 2 intended to examine the way happiness differs between the two groups of respondents with different cultural backgrounds. In addition, this part of the study also investigated whether happiness factors contribute toward affecting people's happiness across the cultures.

The hypotheses that the Swedish respondents have less frequency of negative affect with higher frequency of positive affect and life satisfaction than the Indonesian respondents do was only confirmed for the first one. The two groups of respondents experienced different states of negative affect, in which the Indonesian respondents experienced more negative affect compared to their Swedish counterparts. However, they experienced relatively the same degree of positive affect and life satisfaction.

The finding coincides with the study of Wirtz et al. (2009) showing that people in collectivistic cultures have tendencies to feel negative emotions. However, at the same time, the result did not confirm previous research suggesting that people from collectivist cultures tend to underestimate their life satisfaction, while individualistic people were more likely to overestimate their life satisfaction judgment (Diener, et al., 2003). The result was also not in accordance with a study conducted by Oishi and Diener (2003) and Wirtz et al. (2009), which suggested that people in individualistic countries had a tendency to show a higher degree of positive affect. Although the Indonesian respondents had the same degree of positive affect and life satisfaction as the Swedish respondents, they had greater tendencies to feel more negative affect.

According to Lu and Gilmour (2004), people in collectivistic countries tend to consider social desirability 
and attribute negative affect to themselves. They experience negative affect in a longer period of time than people from individualistic countries do. According to Wirtz et al. (2009), collectivistic people have a tendency to recall not only positive affect but also negative affect compared to individualistic people who more often recall positive affect only. Consequently, the collectivistic people are more likely to experience a higher degree of negative affect than the individualistic people.

This study also found no difference between the cultures with regard to their subjective well-being. This finding suggested that subjective well-being was reflected not only by one component but by all of the three components, which are moderately correlated but separable, as stated by Diener (1984). The two groups of respondents experienced different degrees of negative affect. However, the result did not indicate that one group was less happy than the other. Their positive affect and life satisfaction did also contribute to their subjective well-being.

Another intriguing finding was that subjective well-being differed between the groups of respondents with regard to their happiness factors. Despite not confirming the hypothesis on the effect of culture on the level of happiness, this study found a strong effect of happiness factors, independent of their interaction with cultures, on the level of subjective well-being. In particular, the finding showed that people who are happy due to interdependent factors tended to experience higher subjective well-being than those who reported independent factors of happiness, regardless of the culture they were in.

This finding does not provide any support to Diener, Diener, and Diener (1995) whose work suggested that people who pursue happiness with self-fulfillment and focus on achieving personal happiness were more likely to have a higher degree of subjective well-being than those who pursue happiness by focusing on communal happiness. By contrast, either the Indonesian or Swedish respondents who mentioned interdependent factors as the matters that made them happy, experienced more subjective well-being than those who reported personal factors as their happiness contributors.

Garcia, Schütz, MacDonald, and Archer (2016) could offer an alternative explanation for this issue. In their studies, they found that happier people who scored high on positive affect with either high or low negative affect (i.e., having self-fulfilling or high affective profile) were more likely to choose social affiliation as the happiness-increasing strategy. By contrast, people who scored low on positive affect were less likely to opt for social affiliation in promoting their happiness. In other words, communal aspects and activities might be the factors that can leverage happiness for people.

\section{General findings and discussion}

The purpose of this study was to compare subjective well-being among people in Indonesia and Sweden in terms of factors that contribute to their happiness and level of subjective well-being. The quantitative result suggested no difference between the cultures with regard to the level of subjective well-being, while the qualitative result showed that both the Indonesian and Swedish respondents were happy mainly due to interdependent factors in their lives. In addition, our study found that culture did not have an effect on the level of subjective well-being. There was no difference in the level of subjective well-being with regard to the culture. Instead, the happiness factors were more important in influencing the level of subjective well-being in which people who pursued an interdependent type of happiness were happier than those who mentioned independent factors as their happiness contributor.

This study contributes in several ways to emerging literature on happiness. First, to the best of our knowledge, this study is the first empirical cross-cultural happiness study conducted in Southeast Asia and Scandinavian countries. Second, our study provides evidence that people in individualistic cultures are not always happier than those in collectivistic cultures. Individualistic (versus collectivistic) values cannot always help to describe the way people think, feel, and behave in a particular culture. This study also shows that people who consider interdependent factors as their happiness contributors are happier than those who pursue a personal 
A’yuninnisa, R. N., \& Adrianson, L.

form of happiness. Finally, practically, the finding of this study suggests that the promotion of happiness among people in both countries can be afforded by considering the contributing factors of happiness which are mainly related to interpersonal relation and social life.

Despite its strengths, this study has several limitations that require a cautious interpretation of the results. First, we recognize that the scales and procedure of data collection might contain errors due to language barriers as the instruments were written in English for both groups of respondents. This condition might affect the reliability of the data and the confidentiality of the findings. Besides, the respondents involved in the present study were only a few university students from the two countries and their gender ratio was not balanced. The number of respondents was not sufficiently representative and consequently, the results could not be generalized.

Having presented the contributions and weaknesses of this study, we recommend that future studies investigate happiness factors across cultures more comprehensively and examine the types of happiness in each culture. We also encourage researchers who intend to conduct a cultural study to consider other characteristics of cultures aside from individualistic (versus collectivistic) values, as well as other cultural dimensions to explain psychological phenomena more effectively.

Acknowledgement - This study was conducted as a part of the Linnaeus Palme Programme, administered by the International Programme Office for Education and Training, and financed by the Swedish International Development Cooperation Agency.

\section{References}

Arrindell, W. A. (1998). Femininity and subjective well-being. In G. Hofstede (Ed.), Masculinity and femininity: The taboo dimension of national culture (pp. 44-52). Thousand Oaks, CA: Sage.

Chapin, M. H., \& Holbert, D. (2009). Differences in affect, life satisfaction, and depression between successfully and unsuccessfully rehabilitated persons with spinal cord injuries. Rehabilitation Counseling Bulletin, 53(1), 6-15. https://doi.org/10.1177/0034355209331403

Diener, E. (1984). Subjective well-being. Psychological Bulletin, 95(3), 542-575. https://doi.org/10.1037/0033-2909.95.3.542

Diener, E. D., Emmons, R. A., Larsen, R. J., \& Griffin, S. (1985). The satisfaction with life scale. Journal of personality assessment, 49(1), 71-75. https://doi.org/10.1207/s15327752jpa4901_13

Diener, E., \& Emmons, R. A. (1984). The independence of positive and negative affect. Journal of Personality and Social Psychology, 47, 1105-1117. https://doi.org/10.1037/0022-3514.47.5.1105

Diener, E., \& Oishi, S. (2000). Money and happiness: Income and subjective well-being across nations. In E. Diener \& M. E. Suh (Eds.), Culture and subjective well-being (pp. 185-218). Cambridge, MA: MIT Press.

Diener, E., Diener, M., \& Diener, C. (1995). Factors predicting the subjective well-being of nations. Journal of Personality and Social Psychology, 69, 851-864. https://doi.org/10.1037/0022-3514.69.5.851

Diener, E., Napa-Scollon, C. K., Oishi, S., Dzokoto, V., \& Suh, E. M. (2000). Positivity and the construction of life satisfaction judgments: Global happiness is not the sum of its parts. Journal of Happiness Studies, 1, 159-176. https://doi.org/10.1023/A:1010031813405

Diener, E., Oishi, S., Richard, E., \& Lucas, R. (2003). Personality, culture, and subjective well-being: Emotional and cognitive evaluations of life. Annual Review of Psychology, 54(1), 403-425. https://doi.org/10.1146/annurev.psych.54.101601.145056

Diener, E., Sandvik, E., \& Pavot, W. (2009). Happiness is the frequency, not the intensity, of positive versus negative affect. Social Indicators Research Series, 39, 213-231. https://doi.org/10.1007/978-90-481-2354-4_10

Diener, E., Smith, H., \& Fujita, F. (1995). The personality structure of affect. Journal of Personality and Social 
Subjective well-being of Indonesian and Swedish college students: A cross-cultural study on happiness

Psychology, 69, 130-141. https://doi.org/10.1037/0022-3514.69.1.130

Diener, E., Suh, E. M., Lucas, R. E., \& Smith, H. L. (1999). Subjective well-being: Three decades of progress. Psychological Bulletin, 125, 276-302. https://doi.org/10.1037/0033-2909.125.2.276

Gallagher, M. W., Lopez, S. J., \& Preacher, K. J. (2009). The hierarchical structure of well-being. Journal of Personality, 77, 1025-1050. https://doi.org/10.1111/j.1467-6494.2009.00573.x

Garcia, D., Schütz, E., MacDonald, S., \& Archer, T. (2016). Differences in happiness- increasing strategies between and within affective profiles. Clinical Experimental Psychology, 2, 139. https://doi.org/10.4172/2471-2701.1000139

Hamama, L., Ronen, T., Shachar, K., \& Rosenbaum, M. (2013). Links between stress, positive and negative affect, and life satisfaction among teachers in special education schools. Journal of Happiness, 14 , 731-751. https://doi.org/10.1007/s10902-012-9352-4

Hitoko, H., \& Uchida, Y. (2015). Interdependent happiness: Theoretical importance and measurement validity. Journal of Happiness Study, 16, 211-237. https://doi.org/10.1007/s10902-014-9505-8

Hofstede, G. H., \& Hofstede, G. J. (2005). Cultures and organizations: Software of the mind. New York: McGraw-Hill.

Kahneman, D., Diener, E., \& Schwarz, N. (1999). Preface. In D. Kahneman, E. Diener, \& N. Schwarz (Eds.), Well-Being: The foundations of hedonic psychology (pp. ix-xi). New York: Russell Sage Foundation.

Kitayama, S., Park, H., Sevincer, A. T., Karasawa, M., \& Uskul, A. K. (2009). A cultural task analysis of implicit independence: Comparing North America, Wester, Europe, and East Asia. Journal of Personality and Social Psychology, 97(2), 236-255. https://doi.org/10.1037/a0015999

Kokko, K., Korkalainen, A., Lyyra, A., \& Feldt, T. (2013). Structure and continuity of well-being in mid-adulthood: A longitudinal study. Journal of Happiness Study, 14(1), 99-144. https://doi.org/10.1007/s10902-011-9318-y

Krippendorff, K. (2004). Content analysis: An introduction to its methodology. California: Sage.

Lu, L., \& Gilmour, R. (2004). Culture and conceptions of happiness: individual oriented and social oriented swb. Journal of Happiness Studies, 5, 269-291. https://doi.org/10.1007/s10902-004-8789-5

Lucas, R. E., \& Diener, E. (2008). Subjective well-being. In M. Lewis \& J. M. Haviland-Jones (Eds.), Handbook of emotions (3rd ed., pp. 471-484). New York: The Guilford Press.

Markus, H. R., \& Kitayama, S. (1991). Culture and the self: Implication for cognition, emotion, and motivation. Psychological Review, 98(2), 224-253. https://doi.org/10.1037/0033-295X.98.2.224

Oishi, S., \& Diener, E. (2001). Goals, culture, and subjective well-being. Personality and Social Psychology Bulletin, 27, 1674-1682. https://doi.org/10.1177/01461672012712010

Oishi, S., \& Diener, E. (2003). Culture and well-being: the cycle of action, evaluation, and decision. Personality and Social Psychology Bulletin, 29(8), 939-949. https://doi.org/10.1177/0146167203252802

Oishi, S., Graham, J., Kesebir, S., Galinha, I. C. (2013). Concept of happiness across time and cultures. Personality and Social Psychology Bulletin, 39(5), 559-577. https://doi.org/10.1177/0146167213480042

Proctor, C., Linley, P. A., \& Maltby, J. (2010). Very happy youths: Benefits of very high life satisfaction among adolescents. Social Indicator Research, 98, 519-532. https://doi.org/10.1007/s11205-009-9562-2

Sheldon, K. M., Elliot, A. J., Chirkov, V., Kim, Y., Wu, C., Demir, M., \& Sun, Z. (2004). Self-concordance and subjective well-being in four cultures. Journal of Cross-cultural Psychology, 35, 209-223. https://doi.org/10.1177/0022022103262245

Suh, E. M., \& Oishi, S. (2004). Culture and subjective well-being: Introduction to the special issue. Journal of Happiness Studies, 5, 219-222. https://doi.org/10.1007/s10902-004-8783-y

Triandis, H. C. (1995). Individualism and collectivism. Boulder: Westview Press.

Uchida, Y., Norasakkunkit, V., \& Kitayama, S. (2004). Cultural constructions of happiness: Theory and empirical evidence. Journal of Happiness Studies, 5, 223-239. https://doi.org/10.1007/s10902-004-8785-9

Watson, D., Clark, L. A., \& Tellegen, A. (1988). Development and validation of brief measures of positive and negative affect: The PANAS scales. Journal of Personality and Social Psychology, 54, 1063-1070. https://doi.org/10.1037/0022-3514.54.6.1063 
A’yuninnisa, R. N., \& Adrianson, L.

Wirtz, D., Chiu, C., Diener, E., \& Oishi, S. (2009). What constitutes a good life? Cultural differences in the role of positive and negative affect in subjective well-being. Journal of Personality, 77, 1167-1196. https://doi.org/10.1111/j.1467-6494.2009.00578.x

Ye, D. Y., Ng, Y. K., \& Lian, Y. (2015). Culture and happiness. Social Indicator Research, 123, 519-547. https://doi.org/10.1007/s11205-014-0747-y 